ial, so that an accretion process became impossible, and in that region we now have the asteroid belt. Some 10,000 asteroids have been discovered, and one thousand of these, of more than one kilometre in size, cross the orbit of the Earth. Professor Taylor's estimate of the chance of another celestial collision, similar to that which led to the extinction of the dinosaurs, places the uniqueness of our existence in perspective. So, too, does his estimate that we would be unlikely to exist but for the fortunate circumstances that led to the formation of the planet Jupiter, which, because of its gravitational effect, has saved us from frequent bombardment by comets.

In the last section of this book, Professor Taylor reveals the reason for his title. He believes that his account shows that only chance events have led to the evolution of the Solar System, of the existence of the Earth and of life. He believes that the sequence of these chance encounters makes life on Earth unique in the Universe and that searches for life elsewhere are futile. Many readers may feel that this last section, with its anti-religious undertones, is an unnecessary and unworthy conclusion to an otherwise easily readable account of the formation of the Solar System.

Bernard Lovell is at the Nuffield Radio Astronomy Laboratories, University of Manchester, Jodrell Bank, Macclesfield, Cheshire SK11 9DN, UK.

\section{Fat and fiction: time to weigh the benefits}

\section{The Fats of Life}

by Caroline M. Pond

Cambridge University Press: 1998. 328pp.

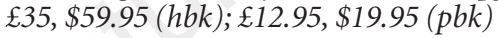

\section{John Prins}

Is fat friend or foe? This question has vexed people for an age, but in recent times has been somewhat forgotten, with fat firmly ensconced as villain. In The Fats of Life, Caroline Pond aims to redress the balance, championing the cause of fat and its many intimate associates, including lipids, blubber and fat-soluble vitamins.

Pond gathers her evidence from many sources - most prominently her own field of comparative biology, but also archaeology, plant biology, historic writings and even mythology. This can make for fascinating reading, but is occasionally somewhat repetitive. Another problem is that, for much discussion, argument and presented 'fact', no references are given. Indeed, in much of the book, the anecdotes are better referenced than the science - a feature that will irritate the scientific but may not trouble the lay reader, as it is the anecdotes that most beckon further reading.

The book's stated aim is to "fill the gap

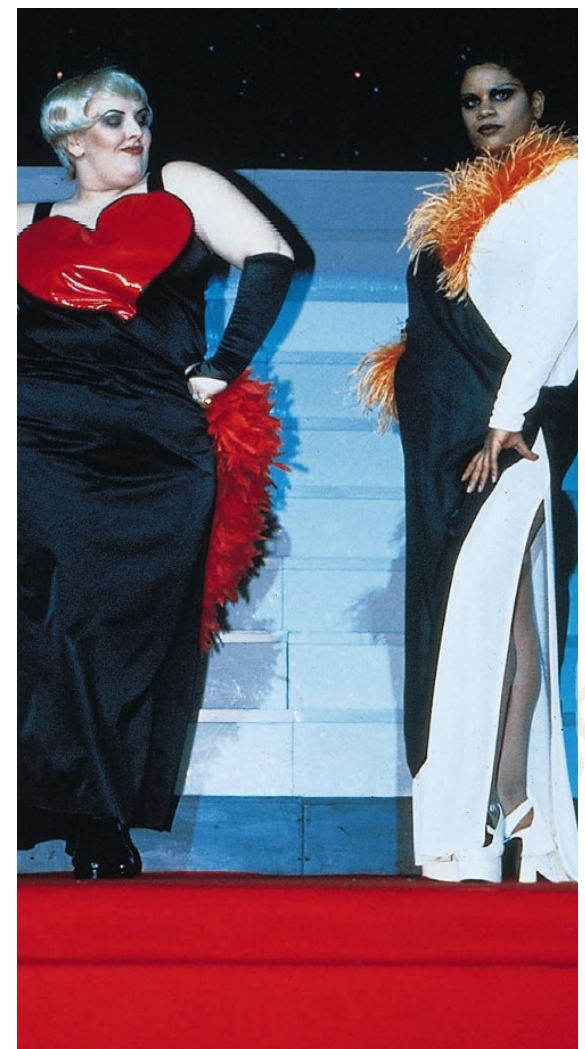

Edmond Boublil's "Ronde de Nuit" line on show in Paris.

between unscientific comments about the hazards and benefits of high-fat or low-fat diets and weight control found in magazines, and technical and medical reports about lipid biochemistry and obesity". Thus readers would hope to learn about the role of fat in their own bodies, its likely advantages and disadvantages, and perhaps gain some insight into how their weight may be modified if desired.

Unfortunately, while much of this information can be found in the book, it is rather scattered about. The reader comes away with no clear impression of whether overweight or obesity is truly bad, or if it may even be good. The energy balance equation is discussed or alluded to in various chapters, but its overriding importance is never made clear. For example, in weight control, dietary

\section{New in paperback}

\section{What Emotions Really Are}

\section{by Paul E. Griffiths}

University of Chicago Press: 1998. 286pp. \$17, $£ 13.50$

"It is difficult to do justice to Griffiths in a short review. His analysis of the concept of emotion and his proposal for the future direction of the field is the most compelling and best argued I have read. What Emotions Really Are makes a strong claim to be one of the best books to have emerged on the subject of human emotion." Ray Dolan, Nature 391, 35-36 (1998). fat content only really makes a difference if there is a positive energy balance, meaning that you are consuming more calories than you are using up; but, while this crucial point is well made, it is also well hidden. Furthermore, Pond's arguments on the value of fat often draw on the consequences of extreme low-body-fat situations such as starvation and anorexia. This is no different from extrapolating backwards from studies of individuals with morbid obesity — an extrapolation about which Pond is critical. Similarly, the book concentrates on the metabolic aspects of fat biology and consequences of obesity, as opposed to those that are less (scientifically) trendy, such as psychiatric and orthopaedic problems, and increased rates of malignancy. No one would dispute that, in terms of cardiovascular disease or non insulin-dependent diabetes, it is better to have lipids inside, rather than outside, fat cells. But as many individuals, as well as any rheumatologist, orthopaedic surgeon, plastic surgeon or psychiatrist, will testify, excess lipid stored within fat cells may also have adverse consequences, including osteoarthritis, low self-esteem or depression, and discrimination.

The Fats of Life does not present an altogether balanced view, but there, in fact, lies part of its attraction. Its major contribution may well be to help swing the pendulum back a little, widening the recognition that in order to be healthy, one does not need to be anorexic or nearly so.

John Prins is in the Departments of Medicine and Clinical Biochemistry, Addenbrooke's Hospital, Hills Road, Cambridge CB2 2QR, UK.

\section{Complementing for fishes}

\section{The Diversity of Fishes}

by G.S. Helfman, B.B. Collette, D.E. Facey Blackwell Science: 1997. 528pp. £55, \$69.95

\section{Hans Fricke}

A fish is not so much a taxonomic term as a convenient description for aquatic organ-

\section{Mirrors in Mind}

by Richard Gregory

Penguin: 1998. 302pp. £12.99

Reviewed by Simon Altmann in Nature 385, 785 (1997).

\section{Huxley}

by Adrian Desmond

Penguin: 1998. 820pp. 110.99

Part 1 reviewed by W.F. Bynum in Nature 372, 300 (1994) and part 2 by Crispin Tickell, Nature 386, 349 (1997). 

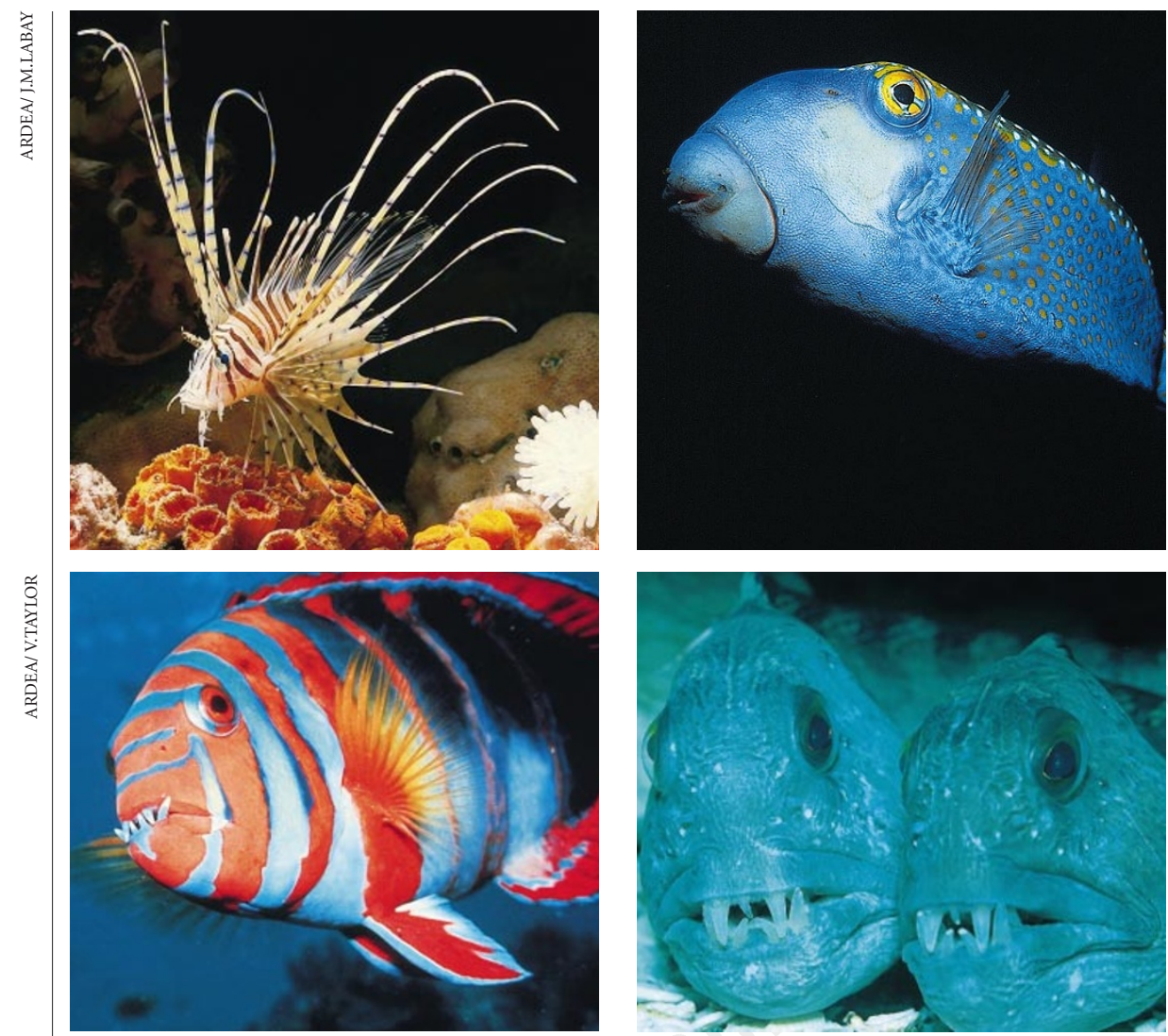

Plenty more fish in the sea: clockwise from top left, lionfish, boxfish, wolf-fish and tuskfish

isms, loosely confined to the vertebrate. In this monumental work, we learn of 49,100 such vertebrates, and that fishes, with more than 50 per cent of the total, do well within the vertebrate world. They are conquerors of the aquatic realm, living almost anywhere, and breaking all sorts of records among the backboned. They thrive at elevations of $5,200 \mathrm{~m}$ in the Himalayas, and at the mephistophelian depths of $8,000 \mathrm{~m}$ in the ocean; and they can live in temperatures at the human pain threshold of almost $50{ }^{\circ} \mathrm{C}$, and, thanks to antifreeze in the blood, down to below zero in Antarctic waters. Amphibians, reptiles, birds and mammals cannot compete.

Fish offer an amazing variety of sex lives. They are promiscuous or polygamous, mate for seconds, or for their entire lives; their sex can be fixed, or they may change it. Both sexes can be simultaneously possessed by one individual, or they can alternate from one to the other. Last but not least, one species even omits the male sex and consists of females only, their eggs activated by the sperm of foreign species. Fishes are the kings of the vertebrates. This book was written by those who admire them, and is directed at those with an interest in them. The authors want to turn this interest into fascination, and they succeed.

In the "shameless self-promoting department" of their website, the authors advertise their work as "far the most complete and detailed ichthyology textbook available". The
Diversity of Fishes is, indeed, a massive enterprise. The book's 25 readable chapters explore the diversity of fish in terms of anatomy, taxonomy, phylogeny, physiology, ecology and behaviour, even science history, and also, importantly, their future. There are endless figures, tables and boxes, the last taking up such snappy matters as "Just what is a bichir?", "Social transmission of cultural trathe politics of endangerment". "We have gone to considerable lengths to get our facts straight or to admit where uncertainties lie", the authors claim, and their honesty extends to a website with updates about misspellings, reversed photographs and art works, faulty figures, and incomplete references.

But having developed in us a tremendous regard for these cold-blooded (except a few of them) "insects" of the aquatic realm, the authors have a surprise for us at the very end. The massive reference section carries 1,800 citations, but not one of them in a language other than English. Are all original publications in Dutch, German, French, Japanese and Russian (most of them with English summaries) below standard? For example, where is the Nobel laureate Karl von Frisch's classic work on hearing in fish, with the refreshing title Ein Fisch der kommt wenn man pfeift (A fish which comes if one whistles)? A box for von Frisch would have been nice. There are many other works of this calibre in the international non-English literature. ditions in fishes" and "The snail darter and
Hans Fricke is at the Max Planck Institute for Animal Behaviour, 82319 Seewiesen, Germany min Impurities in the historical stream

\section{The Bends: Compressed Air in the History of Science, Diving, and Engineering by John L. Phillips Yale University Press, New Haven and London, 1998. 217pp. plus Notes, Bibliography and Index, $\$ 30.00$ \\ James Vorosmarti}

John Phillips has packed a great deal of information from a wide range of sources into this history of compressed air. For those who have worked and studied in this field none of it is new - contrary to the claims of the dustjacket, there is no evidence that the author drew on previously unpublished letters, diaries and notes, and, ironically, the book is not very informative about the bends itself. But in general, The Bends is well done.

The author has for the most part correctly identified the major advances in the use of compressed air in diving and caisson work and those who made them. The chapters dealing with Charles-Jean Triger, James Eads and the first bridge across the Mississippi, the physician Alphonse Jaminet (who contracted the bends), and the Brooklyn Bridge are all well written and provide interesting reading to those who are not familiar with the pioneering engineering of this area of civil engineering.

What is irritating and detracts from the volume are the many examples of careless writing or editing. In one instance, Phillips states that compressed air was invented in the 1840 s, when there is evidence in the text that compressed air was known well before this. Thomas Smeaton did invent the first practical air compressor, but he did not unite compressors with steam power. Phillips ignores F. Hoppe, the first scientist to show that on decompression free gas could be found in the heart and the great veins leading to it, and, in 1857 , rightly attributed death in caisson workers to this liberation of gas from the blood and tissues. This was before Paul Bert's similar demonstration, and his discovery that the bubbles were mainly nitrogen.

Phillips does not include Bert's important conclusions that oxygen and recompression would be useful in the treatment of decompression sickness (DCS). He repeats the myth that Augustus Siebe invented the diving helmet in 1819 (invented by Charles and James Deane in 1828), although Siebe did produce the first closed diving dress in 1839 , which was the model for deep-sea diving dress into the 1970s. He first uses the term SCUBA for the Denayrouse-Royquayrol apparatus of 1865, while missing the fact that 